\title{
Research on Training Status and Countermeasure of Strength and Conditioning Coaches in China
}

\author{
Yan Li \\ Hebei Institute of Physical Education 050041, \\ Email: 878578182@qq.com
}

\author{
Huanbin Zhao \\ Institute of Physical Education, Hebei \\ Normal University 050024 \\ 82 Xuefu Road, Shijiazhuang, Hebei 050041 China
}

\begin{abstract}
In this paper, the present situation of strength and conditioning coaches in China and the training status of domestic and overseas strength and conditioning coaches are analyzed, it is found that there are many problems about the training for strength and conditioning coaches, such as the insufficient system planning and imperfect training system and the inadequate scientific support; through learning $s$ from internationally-advanced training concept and combining with the reality in China, the countermeasures and suggestions on the training for Chinese strength and conditioning coaches are proposed.
\end{abstract}

Keywords- strength and conditioning coaches; training status; countermeasure research

After Beijing Olympic Games, General Secretary $\mathrm{Hu}$ Jintao proposed the objective of struggle for promoting China to stride forward from a great sporting country to a powerful sporting country; and the competitive sports are given more difficult tasks and glorious mission. In 2011, Party Central Committee proposed the strategic goal that China will be built into the powerful country with talents until 2020. The strategies of the country with powerful sports and talents can not be achieved without a large number of high-quality and high-level coaches with international vision, strategic thinking and innovation ability. Coaches are an important team for Chinese sports. They are not only the training designers, organizers and practitioners, but also the educators and director of the athletes, as well as the key talents of the competitive sports and the important human resources of competitive sports. Their quality level is an important factor to affect the development of competitive sports in China, and directly related to the implementation of the Program of striving for Olympic Glory and the development of sports cause. In order to promote the construction of high-quality coach team in China, the State Sport General Administration specially approved a project to focus on cultivating 100 coaches for professional team and 100 coaches for amateur training, and strive to build a leading coaching team.

\section{THE PRESENT SITUATION OF STRENGTH AND CONDITIONING COACH COACHES IN CHINA}

In China, the strength and conditioning coach is an emerging profession. According to the present situation, parts of the national and professional teams can hire the foreign strength and conditioning coaches with high salary, but most coaches of other teams act as the guest performers from track and field events. Even so, not each team has the strength and conditioning coach. The director from Department of Science, Technology and Education of the State Sport General Administration Jiang Zhi expressed that the physical ability is not only the foundation of sports technique and the root of special training, but also the effective guarantee to prevent injuries and diseases. At present, the scarcest resources are strength and conditioning coaches. In the face of the present situation of the scarcest strength and conditioning professional talents in China, it is a top priority to cultivate a group of high-level strength and conditioning coaches. However, there is no institution or organization in our country to promote the professionalization process of strength and conditioning coaches; and all strength and conditioning coaches are appointed by the national teams and professional clubs according to their own needs and degree of recognition. The present strength and conditioning coaches are in fuzzy state with insufficient post staffing, appointment standard and management; due to the defects of mechanism, the strength and conditioning coaches are generally low in coaching level, so that the improvement of scientific level of Chinese physical training is troubled and hindered. Strength and conditioning coach is the key talent in competitive sports. The insufficient strength and conditioning coaches have direct influence on raising the level of competitive sports in China, and hindering the implementation of the Program of striving for Olympic Glory and the development of sports cause, even inconformity with the strategic policy of sports talents based on "invigorating country based on talents and enhancing sports cause based on talents".

\section{THE TRAINING STATUS OF THE STRENGTH AND CONDITIONING COACHES AT HOME AND ABROAD}

In the United Kingdom, the Sports Conditioning and Coaching Course is taught in the University of The West of England, Bristol (Bristol UWE). In Australia, the Strength \& Conditioning Course is also taught in the University of Canberra, Deakin University, the University of Queensland and Edith Cowan University; in Germany, other courses oriented with sports science will last four years, but the courses oriented with physical training will last five years. However, as the world's first power of science\& technology and sports, the United States attached more importance to cultivating strength and 
conditioning coaches; in 1988, Indianapolis invested \$12 million to build the "national institute of physical ability and sports". In the American sports colleges and universities, the physical conditioning courses are taught in general. Internationally, the most prestigious American National Strength and Conditioning Association (hereinafter referred to as the NSCA) is an excellent organization to cultivate the strength and conditioning coaches. NACA cultivated the experts in many fields, including the sports science, athletic training and applied health and fitness industry, devoted to achieving the application and conversion of the latest research findings of strength and conditioning training, and regarded the strength and conditioning training as a discipline and specialty to develop. At present, there are more than 100,000 NSCA members across 52 countries. A lot of advanced knowledge and research findings related to strength training, quality training and injury prevention are developed and proposed. In recent years, American physical training centers have successively established and sprung up like mushrooms, and cultivated the excellent strength and conditioning coaches in the world.

In China, the cultivation of strength and conditioning coaches is relatively late; in 2004, Beijing Sport University established the first national strength and conditioning training experiment class; Guangzhou Physical Education Institute set up the special teaching class majoring in strength and conditioning in 2005. The Physical Education Institute of Hebei Normal University set up the strength and conditioning class in 2008; Chengdu Sport University established the science of strength and conditioning training and physical training course; Wuhan Institute of Physical Education set up the strength and conditioning course. Shanghai Institute of Physical Education set up the evaluation theory and approach courses of physical fitness; Guangzhou Physical Education Institute set up the theory and practice courses of strength and conditioning training. However, due to lack of the clear and unified training specifications, standards and the teaching materials, the cultivated physical training talents based on such methods are also uneven in quality.

\section{THE MAIN PROBLEMS OF CULTIVATING THE STRENGTH AND CONDITIONING COACHES IN CHINA}

- A. The training of national strength and conditioning coaches is lack of systematic planning

In terms of the general administration of sports, the provincial or municipal sports bureau, the multiple-management phenomenon appears in the training of strength and conditioning coaches to a certain extent; there is no clear administrative organizations to implement the overall planning on the national strength and conditioning coaches, so that the training work is lack of clear responsibility, the resources are scattered, and the repeated training often occurs; all these factors affect the training quality and benefits of the coaches to some extent.

\section{- $\quad$ B. The training system of strength and conditioning coaches are imperfect}

On-the-job training is relatively mature system of coach training in China; however, along with the scientific development of modern competitive sports, the disadvantages of the on-the-job training are increasingly prominent. At present, the competitive sports powers in the world generally adopt hierarchy certification system with the coaching-based grading standards of the strength and conditioning coaches. However, in Chinese on-the-job training system, the coaching objects in the face of the trainers with the same professional title are different, and the reasonable standards of on-the-job training courses are difficult to formulate; therefore, on-the-job training system decouples with the actual job demands and the career development of the coaches. Secondly, the further education of Chinese strength and conditioning coaches hasn't yet established a set of long-term and effective supervision mechanism. The existing problems of the training system seriously restrict the further improvement of the training quality for coaches.

- C. The training of strength and conditioning coaches is lack of the sustainable scientific support.

Since 2008, in order to improve the comprehensive coaching ability of Chinese strength and conditioning coaches rapidly in a short time, the training is developed in the way of direct introduction of the courses from the world's powers with competitive sports; however, the original training resources based on independent research and development are very limited; in this case, the crisis that we must face is that the foreign training courses will eventually be exhausted one day through years of excavation. If there is no independent research and development, even the foreign resources are inexhaustible, we just follow others passively; moreover, it is difficult for us to have the chance to take the lead in the educational training of the international coaches.

\section{COUNTERMEASURES AND SUGGESTIONS}

- A. Improve the on-the-job training system and construct the training system of strength and conditioning coaches with Chinese characteristics

Through learning the successful experience with grading training certification system of strength and conditioning coaches from the world powers with competitive sports and combining with the specific situation of Chinese competitive sport system reform, the reform and improvement of the current on-the-job training system is implemented; on this basis, the educational training system of the strength and conditioning coaches with Chinese characteristics is constructed.

\section{- B. Learn the experience from NSCA and rapidly promote the development of physical training in China}

Firstly, it is recommended to introduce the qualification certification system of strength and conditioning coaches from the United States and conduct the certification training on Chinese coaches. Secondly, it is recommended to set up the special posts of strength and conditioning coaches in the national teams and provincial outstanding sports teams, and conduct the training certification on these incumbent coaches. Finally, it is recommended to unify the recognition with reference to 
NSCA model and form the physical training content system with Chinese characteristics, so as to avoid the passive situation that Chinese strength and conditioning training has been lagged behind the world powers with competitive sports for a long time.

\section{- C. Improve the training administration mechanism of the strength and conditioning coaches and strengthen the supervision}

It is recommended to establish the industry access system of the strength and conditioning coaches as soon as possible and strengthen the on-board training of the strength and conditioning coaches. Establish the training certification and the update system of the strength and conditioning coaches, and form the linkage mechanism with the registration management, the competition for the post, eligibility and the title promotion, so as to further stimulate the training enthusiasm of the strength and conditioning coaches.

- D. Improve the level of independent research and development, and provide the sustainable motive power for cultivating the strength and conditioning coaches

Conduct the survey on the training demands of the national strength and conditioning coaches, and provide the decision-making basis for formulating the related policies of the educational training for strength and conditioning coaches; conduct overall planning for the educational training of the strength and conditioning coaches, prepare the training course system for the strength and conditioning coaches, organize the experts in various fields to develop the training courses, publish the training materials, and provide the sustainable the driving force for supporting the cultivation of the strength and conditioning coaches.

\section{REFERENCE}

[1] Director Liu's speech on conference of the directors of sports bureau all over the country in 2012. Website of the State Sport General Administration. December 26th, 2012

[2] Notice of the guiding opinion of further strengthening cultural education and security work of the athletes issued by General Office of the State Council on behalf of the State Sport General Administration, No. 23 (2010) issued by General Office of the State Council.

[3] Han Leilei. Research on Chinese sport system reform of striding forward from a great sporting country to a powerful sporting country in the period of transition [D]. Changsha: Hunan Normal University, 2011.

[4] Zhang Xiaolin. Comparative study of management system and operational mechanism on Sino-American competitive sports [D]. Beijing: Beijing Sport University, 2011.

Li Yan (1979 - ), Associate professor, doctoral candidates, Research Interests: Sociology of Sport, the sports industry; Zhao Huan-bin (1956 - ), male, professor, doctor tutor, Research Interests: Physical Education and Training. 